vol.1 No.1 ISSN:18235-2014

\title{
Internship Program Strengths and Weaknesses as Perceived by Nurses Intern By
}

\author{
${ }^{1}$ WalaaMursyHalema, ${ }^{2}$ Fouada Mohamed Shaban, \\ ${ }^{3}$ Seham Ibrahiem Hamouda , ${ }^{4}$ Karima Ahmed El-Sayed. \\ 1,2,3,4, Nursing Administration Department, Faculty of Nursing-Tanta University \\ E-mail of corresponding author: dr.karima ahmed @yahoo.com
}

\begin{abstract}
:
Background: Clinical nursing internship program provides tremendous opportunities for nursing students to successfully transfer from educational classroom to clinical settings. Under one year supervision, nurses intern are guided towards mastery of nursing skills and improved patient service. Internships also provide the opportunity to explore various responsibilities in different nursing fields through rotations. Aim of the study: To assess the internship program strengths and weaknesses as perceived by nurses intern of Tanta University Faculty of Nursing. Setting: The study was conducted at Tanta Main University Hospital. Subjects: Sample was included all 289 nurses intern during their internship year training at medical, surgical, neonatal, anaesthia, pediatric, cardiology, obstetrics and gynecology units. Tool: Data was collected by using a questionnaire sheet. It was included three parts. I-Demographic data about the sample, II- emphasis of internship program according to domains of National Competency Standard and III- four subscales (Opportunities offered by clinical environment support, Level of Confidence in nursing practice, Perception to role of preceptor (supervisor) and Perception to Conflicts and rotation).Results and Conclusion: Results revealed that strengths of internship program at Tanta University Hospital as perceived by nurses intern showed that high emphasis put on rotation, level of confidence in nursing practice and domains of competency. While the weaknesses showed that little emphasis put on avoid conflict, role of supervisor and opportunities offered in clinical environment. Recommendations: Prime importance the availability of clinical preceptors, structured orientation program, coordination between faculty and hospital, evaluating system and feedback and strategies to avoid conflict and lateral violence.
\end{abstract}

Key words: internship program, strengths, weaknesses

\section{Introduction:}

Nursing internship is one year program for baccalaureate nursing graduates who will be employed as staff nurses on clinical units $(1,2)$. The goals of the internship program are to facilitate transition of the new graduates' nurses to professional registered nurses, prepare the beginning level staff nurses who are confident, competent and provide safe patient care ${ }^{(3)}$. Internship combines academic learning with supervised practical experience and serves as a link from the classroom to the work place. It provides nurses intern with the opportunity to earn academic credit and professional work experience through acquiring a true and realistic sense of job expectation, the workplace environment, skills and attitudes needed ${ }^{(4,5)}$.

During internship year, the baccalaureate graduates are paid the salary and benefits of beginning staff nurses and are defined by job code as nursing interns. Nurses intern collaborate with other members of healthcare team ${ }^{(2,6)}$. The internship experience and socialization into the professional role of the nurse assist the nurses intern to understand the demands and expectations they will experience as new graduates. This in turn can decrease the amount of role conflict and anxiety during the transition to the graduate nurse role ${ }^{(7)}$. Indeed internship program enhances nurses interns' competences and facilitates them to advance more quickly from novices to competent nurses by lessening time as advanced beginners ${ }^{(8,9)}$. For nursing, competence is the knowledge, skills, abilities and behaviors that nurses need to perform their work in a professional standard ${ }^{(10)}$. It includes ten competency standards which are involving the responsibilities related to four domains. These domains are professional and ethical practice, critical thinking and analysis, management of care and enabling ${ }^{(11)}$.

Nurses intern who complete a nursing internship program have more professional 
self-confidence and job satisfaction because they are in a supportive environment which offers opportunities for professional growth and autonomy. This supportive environment helps the nurses intern to participate actively as members of the clinical team ${ }^{(12,13)}$.

By implementing internship program, nurses intern will have the necessary support to guide them through the clinical and emotional challenges of their first year as professional nurses ${ }^{(14,15)}$. It provides clinical supervision that is tailorated to match the nurses intern's skills. This concept of supervision involves various roles for the clinical supervisor as teacher, model, coach, counselor, and peer ${ }^{(16)}$. For nurses' intern, they rotate to various units in the hospital through specialty areas and accommodate different shifts. The rotations included general as well as intensive care units within the hospital ${ }^{(11)}$. As a result, It allowed them to learn both unit and hospital policies ${ }^{(17)}$.

Usually, some formal class work is associated with the experience but majority of the time is spent in the direct patient care often under the supervision ${ }^{(18)}$. During a yearlong program, nurses intern can have social and reality integration ${ }^{(19)}$.So they find themselves as practitioners with new roles, responsibilities, and accountability for their practice while they are still learning and developing their knowledge and skills ${ }^{(20)}$.

At the end of the training year, nurses intern are expected to be able to function as competent and ethical professional. Who are equipped to provide various clinical services from generalist perspective? More specially, the nurses intern's competencies which acquired over the course of the training year will prepared the nurses intern to provide effective clinical services to children, adolescent, adults, elderly and their families with the intent to help them, maintain or enhance their quality of life through therapy, assessment and consultation (21). Finally, internship training could have weaknesses such as inadequate staffing patterns, conflict with other healthcare providers, lack of support in dealing with death and dying, unresponsiveness in leadership, poor communication among staff and poor administration, unrealistic expectation, poor support, bullying and lateral violence $(22,23)$

\section{Significance of the study:}

Nurses intern are exposed to many sources of dissatisfaction in clinical environment. It includes inadequate staffing patterns, conflict with other healthcare providers, lack of support in dealing with death and dying, unresponsiveness in leadership, poor communication among staff and poor administration. The disparity in the educational experiences of the student nurses and the expectations of new graduate nurses by healthcare organizations contributes to the overwhelming lack of new nurses' selfconfidence. Thus, this study was conducted to study strengths and weaknesses of internship program.

\section{Operational definitions:}

1-Nurses intern: are defined as new graduate nurses who have completed a baccalaureate nursing degree at the faculty of nursing, Tanta University, and who are responsible for providing professional nursing care to assigned clients under the direct supervision. Nurse interns who are enrolled during the year 2009-2010.

2-Clinical supervisor or preceptor: is an experienced staff nurse who assumes the role of clinical teacher, role model, counselor and resource person for a baccalaureate nurse intern in the clinical setting.

3- Internship year: used synonymously with capstone experience or course, and clinical practicum; concentrated experience in the healthcare environment designed to decrease reality shock by giving students a glimpse of real practice and assisting 
transition into the role of the graduate nurse.

4- Domain: a cluster of competencies that have similar intents, functions and meanings

5- Competency: the ability to fulfill the nursing role effectively and / or expertly across the whole range of competencies applicable to the nurse which result in effective performance that is judged to be appropriate for level of the nurse being assessed ${ }^{(115)}$.

\section{Aim of study:}

This study aimed to assess the internship program strengths and weaknesses as perceived by nurses' intern of Faculty of Nursing at Tanta University.

\section{Study question :}

What are the strengths and weaknesses of the internship program as perceived by nurses intern of Faculty of Nursing at Tanta University?

\section{Subjects \& Methods :}

\section{Study Design:-}

A descriptive design was utilized in the present study.

\section{Setting:-}

The study was conducted at Tanta Main University Hospital. It is a teaching hospital with curative and educational services. The setting is a combination of profit and nonprofit services. It has 902 beds, the units understudy included medical, surgical, neonatal, pediatric, cardiology, obstetrics and gynecology units.

\section{Subjects:-}

All nurses intern (289) have trained at Tanta Main University Hospital during their internship year 2009/2010. Nurses intern train for three months in neonatal, cardiology and anaesthia units. While, they train for a one month in the other units. Nurses intern follow weekly schedule which always between morning, evening, night and days off.

\section{Tools:}

The data of the study was collected by using a questionnaire sheet. It was developed by the researcher guided by recent related researches ${ }^{(24-27)}$, to assess the above mentioned aim.

\section{Tool development:}

1) The tool was presented to jury of five experts in the area of specialty to check the content validity.

The five experts were two professors from Faculty of Nursing Cairo University at Nursing Administration department. Three professors from Faculty of Nursing Alexandria University, two professors from Nursing Administration department and one professor from Critical Care department.

2) The experts were asked to evaluate tool items in relation to its relevance and appropriateness on 4 points rating scale as $1=$ not relevant, $2=$ little relevant, $3=$ relevant and $4=$ strong relevant.

3) Opinions of experts on tool of the study were analyzed and determined the following the face validity $88.61 \%$ and internal consistency reliability 0.8413 . Based on the experts' responses, the researcher takes the items agreed on and works with it.

4) A pilot study was carried out two times on twenty nine nurse's intern out of proposed sample and the questionnaires were given to them again two weeks later to compute test- retest reliability.

-The first time aimed at evaluating the content clarity of the tools; and identifies any obstacles that may be encountered during data collection as confusion about meaning of specific word or item.

- After two weeks, the second time was carried out for the same twenty nine nursing interns. The tool was applied again for evaluating the test - retest reliability, its result was 0.880 .

5) Modifications were done based on the results of pilot study and opinions' panel of five experts. The pilot study was collected from 9th January 2010 to $23^{\text {th }}$ January 2010. The administration time for filling questionnaires' sheets was approximately 20 minutes.

Questionnaire was consisted of three parts. First part contains demographic data about 
the sample. This part was included age, marital status, Previous nursing qualification and graduation level. Part two contains questions on emphasis of internship program according to domains of National Competency Standard was included 20 items classified into four domains namely (1) domain of professional and ethical development 3 items , (2) domain of critical thinking and analysis 5 items , (3) domain of management of care 5 items and (4) domain of enabling 7 items . Part three was included four subscales namely (1) opportunities offered by clinical environment support was included 6 items , (2) level of confidence in nursing practice was included 15 items, (3) perception to role of preceptor was included 4 items and (4) perception to conflicts and rotation was included 18 items .

The nurses intern s' responses were represented into four likert scale ranging from no emphasis to high emphasis. $1=$ no emphasis, 2 = little emphasis, $3=$ moderate emphasis and $4=$ high emphasis. The Scores would be calculated from lowest scores to highest scores, ranging between these classifications into three classes; little was $<60 \%$, moderate was from $60 \%$ to $80 \%$, and high was $>80 \%$.

\section{Methods:}

1) Meetings with head nurse in each unit in the different settings were conducted by the researcher on an individual basis to inform them about the aim of the study.

2) The researcher met with nursing interns in small groups based on their availability and willingness to share during their different work shifts at the units and wards where they train.

3) The nurses intern recorded their answers in the presence of the researcher.

\section{Statistical analysis :}

Results were tabulated and statistical analysis was performed with Statistical Package for Social Science (SPSS version 11). For quantitative data, the range, mean, and standard deviation were calculated. For qualitative data the number and percent was calculated. Correlation between variables was evaluated using Pearson's Correlation. Coefficient. P values of $<0.05$ were considered statistically significant, while $\mathrm{P}$ value of $<0.001$ indicates a high significant result. (115)

\section{Ethical consideration:}

1) An official permission to conduct the study for data collection obtained from responsible authorities.

2) The purpose of the study was explained and clarified to both hospital director and nurse manager of each unit understudy.

3) Nurses intern were told that anonymity would be maintained. They were informed of the purpose of the study and assured that their answers would be kept confidential and would not be used to evaluate them.

\section{Results:}

Table 1 represents that above half 52.6\% of nurses intern had aged $\leq 21$ years with mean age $(21.47 \pm 16.975)$. Less than two thirds of nurses intern $60.2 \%$ were single . Sixty three of nurses intern had grade very good and only $12.6 \%$ had grade excellent. Sixty six of nurses intern were graduated from general secondary school, while 34\% graduated from health technical institute.

Figure 1 revealed that majority of nurses intern $80.6 \%$ perceived high emphasis level of internship program put for total domains of competencies. While only $5.2 \%$ of them perceived little emphasis level. 


Table (1): Demographic Characteristics of Nurses Intern
\begin{tabular}{|l|c|c|}
\hline \multirow{2}{*}{ variables } & The intern nurses (n=289) \\
\cline { 2 - 3 } & & $\mathbf{n}$ \\
\hline Age & 152 & 0.526 \\
$\leq 21$ years & 137 & 0.474 \\
\hline 21 years & \multicolumn{2}{|l|}{} \\
\hline Range 21- 22.8 & 174 & 0.602 \\
Mean \pm SD 21.47 \pm 16.975 & 115 & 0.398 \\
\hline Marital status & & \\
Single & 36 & 0.126 \\
Marriage & 179 & 0.630 \\
\hline Graduate Level & 74 & 0.244 \\
\hline - Excellent & 166 & 0.660 \\
Very Good & 123 & 0.340 \\
\hline Good & & \\
\hline Previous graduation school General Secondary school & Health Technical Institute & \\
\hline
\end{tabular}

Health Technical Institute

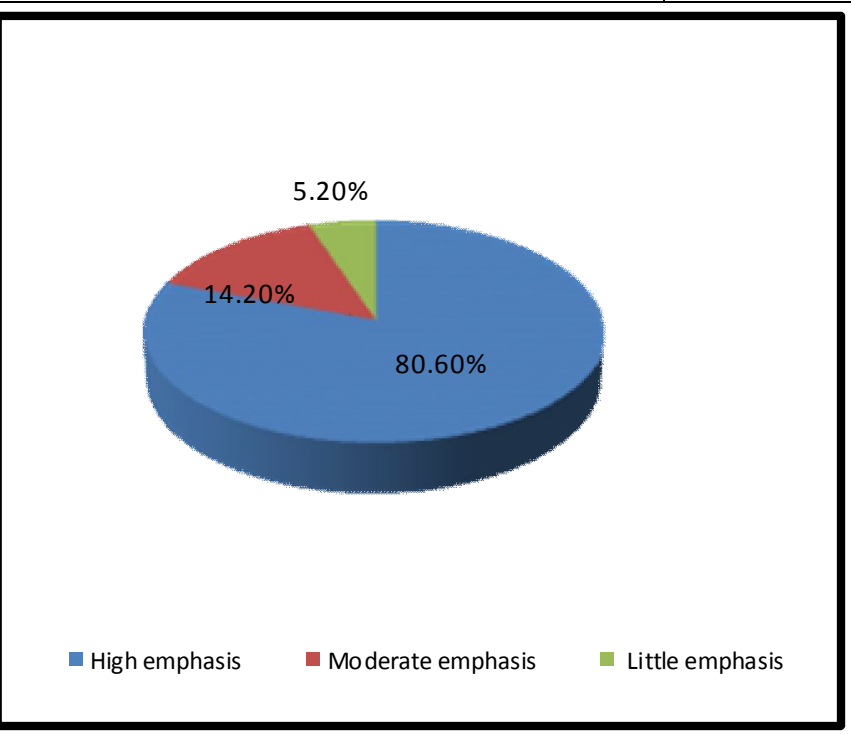

Figure(1): Levels of Internship Program Emphasis on Total Domains of Competency as Perceived by Nurses Intern.

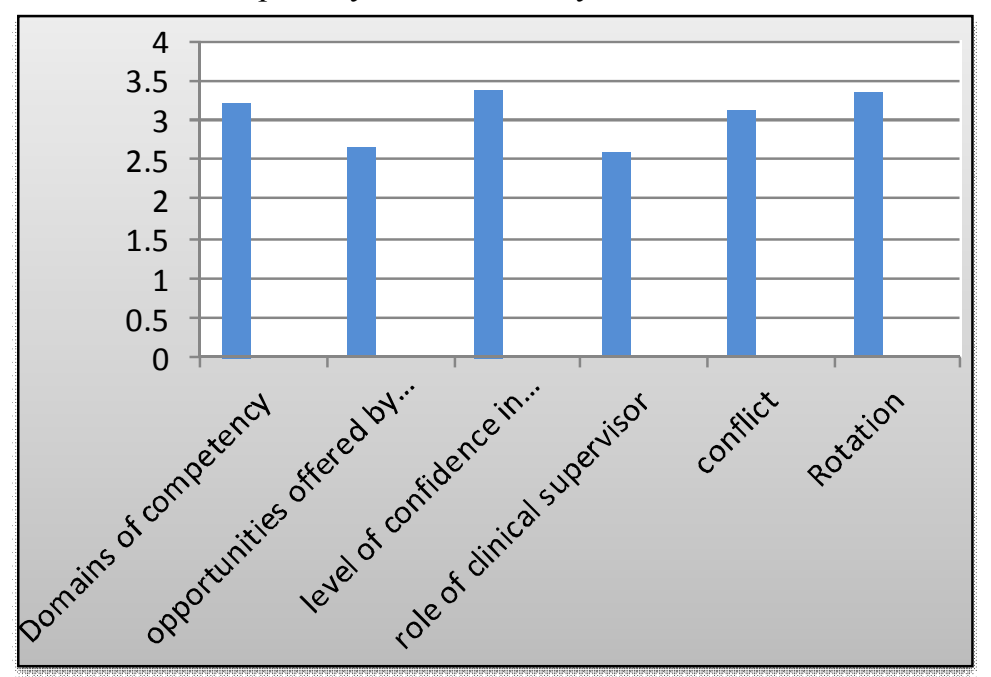

Figure (2) Nursing Interns Mean Perception Score for the levels of Internship Program Emphasis on Its Items. 
Figure 3 demonstrates that high percent of nurses intern $60.5 \%$ perceived that internship program put little emphasis on opportunities offered in clinical environment, while low percent $15 \%$ of them perceived high emphasis level on this domain

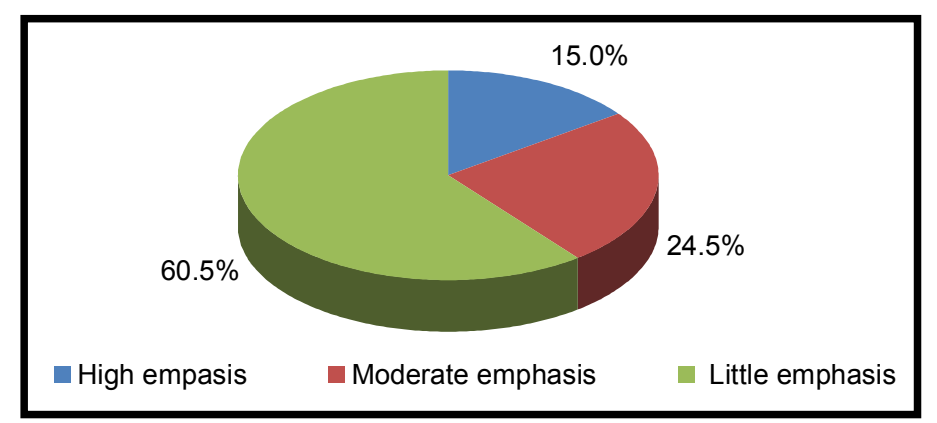

Figure (3): Levels of Internship Program Emphasis on Total Opportunities Offered by Clinical Environment as Perceived by Nurses Intern

Figure 4 shows that majority of nurses intern $87.2 \%$ perceived that internship program put high emphasis on level of confidence in nursing practice. While low percent of them $2.6 \%$ perceived that internship program put moderate and little emphasis level on this domain

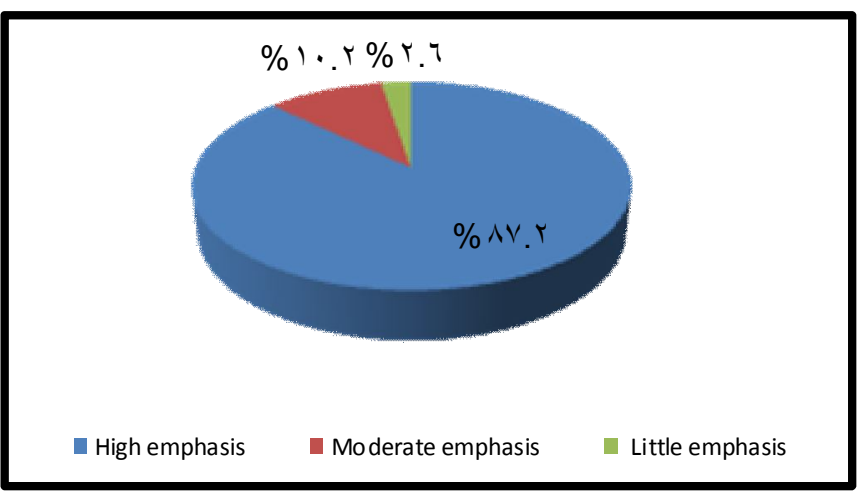

Figure (4) Levels of Internship Program Emphasis on Confidence in Nursing Practice as Perceived by Nurses Intern

Figure 5 revealed that less than two thirds of nurses intern $(63.1 \%)$ perceived that internship program put little emphasis level for role of clinical supervisor. While the minority of them $(15 \%)$ perceived that internship put high emphasis level on this domain

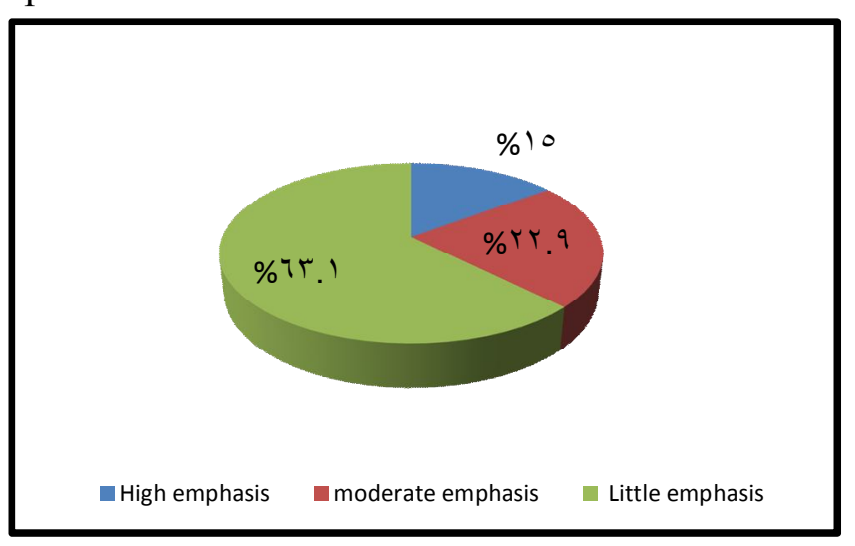

Figure (5) Levels of Internship Program Emphasis on Role of Clinical Supervisor as Perceived by Nurses Intern 
Figure 6 shows that high percent of nurses intern $72 \%$ perceived that internship program put little emphasis level on the conflict management, while low percent of them $12 \%$ perceived that internship program put high emphasis level on this domain

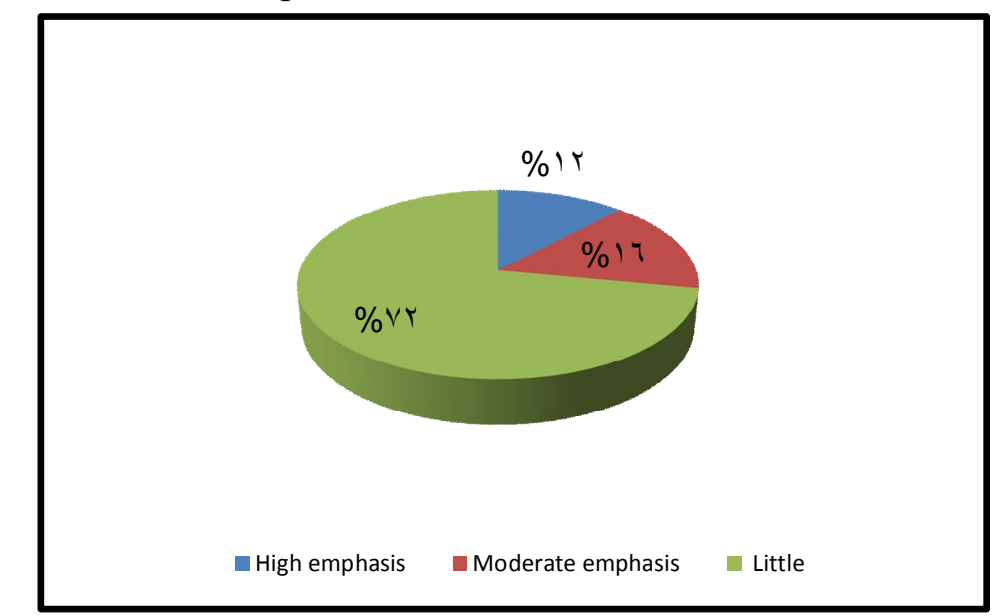

Figure (6) Levels of Internship Program Emphasis on Manage the Conflict as Perceived by Nurses Intern

Figure 7 demonstrates that majority of nurses intern $90.7 \%$ perceived that internship program put high emphasis level on rotation, while the minority of them
$6.1 \%$ and $3.2 \%$ perceived that internship program put little emphasis and moderate emphasis level on it respectively

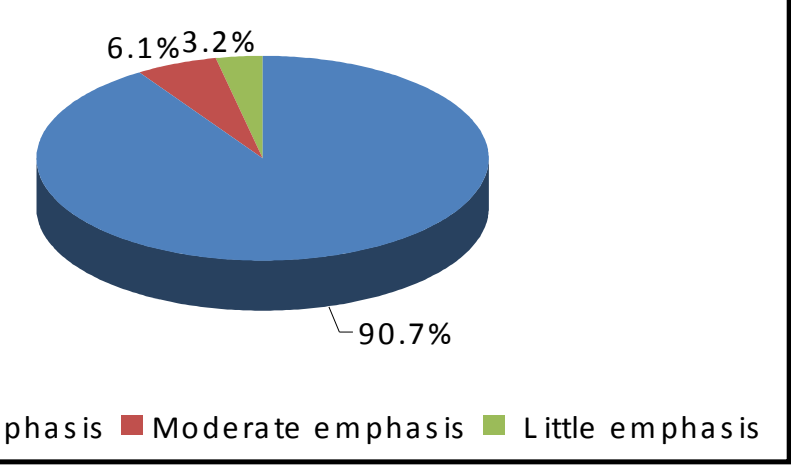

High emphasis Moderate emphasis Little emphasis

Figure (7) Levels of Internship Program Emphasis on Rotation as Perceived by Nurses Intern

Table 2 revealed that significant correlation between all internship program items $(\mathrm{P}<0.001)$. This means when opportunities offered in clinical environment, role of clinical supervisor, rotation and avoiding the conflict increase the level of confidence in nursing practice and domains of competency will increase.
In other words, the internship program attend to provide opportunities in clinical environment, clinical supervision, rotation and avoiding conflict that allows the development of competency and confidence in nursing practice to nurses intern 


\begin{tabular}{|c|c|c|c|c|c|c|}
\hline Items & $\begin{array}{l}\text { Domains of } \\
\text { competency }\end{array}$ & $\begin{array}{l}\text { Opportunities } \\
\text { in clinical } \\
\text { environment }\end{array}$ & $\begin{array}{l}\text { Level of } \\
\text { confidence }\end{array}$ & $\begin{array}{l}\text { Role of } \\
\text { supervisor }\end{array}$ & $\begin{array}{l}\text { Avoid } \\
\text { conflict }\end{array}$ & Rotation \\
\hline $\begin{array}{l}\text { Domains of } \\
\text { competency }\end{array}$ & & $.371 * *$ & $.440 * *$ & $.433 * *$ & $.595 * *$ & $.372 * *$ \\
\hline $\begin{array}{l}\text { Opportunitie } \\
\text { in clinical } \\
\text { environment }\end{array}$ & $.371 * *$ & & $.536 * *$ & $.364 * *$ & $.455^{* *}$ & $.417 * *$ \\
\hline $\begin{array}{l}\text { Level of } \\
\text { confidence }\end{array}$ & $.440 * *$ & $.536^{* *}$ & & $.348 * *$ & $.627 * *$ & $.377 * *$ \\
\hline $\begin{array}{l}\text { Role of } \\
\text { supervisor }\end{array}$ & $.433 * *$ & $.364 * *$ & $.348 * *$ & & $.664 * *$ & $.475^{* *}$ \\
\hline $\begin{array}{l}\begin{array}{l}\text { Avoid } \\
\text { conflict }\end{array} \\
\end{array}$ & $.595 * *$ & $.455^{* *}$ & $.627 * *$ & $.664 * *$ & & $.322 * *$ \\
\hline Rotation & $.372 * *$ & $.417 * *$ & $.377 * *$ & $.475^{* *}$ & $.322 * *$ & \\
\hline
\end{tabular}

N.B

$*$ = Correlation is significant at the 0.05 level

$* *=$ Correlation is highly significant at the 0.01 level

\section{Discussion:}

The internship year is an important part of undergraduate education, training and preparation of new graduates for clinical practice ${ }^{(3)}$. Internship program plays an important role in improving the work performance of the new nurses and establishes their attitudes toward the organizations they work. Therefore, the implementation of the internship program provides them with career development advice and psychosocial support ${ }^{(8)}$.

The present study revealed that majority of nurses intern perceived high emphasis level of internship program put on total domains of competencies. This may be related to that internship program assists nurses intern to develop their fundamental clinical skills. Indeed they perform a lot of work in a short time and they practice side by side with the professional healthcare team. In this respect, Duchscher (2008) ${ }^{(28)}$, Evans $(2009)^{(29)}$, Good et al $(2009)^{(30)}$, and Ashlock et al $(2010)^{(31)}$ supported the results of the present study and they found the nurses intern reported that the internship emphasis on all domains of competency was high.

Within Egypt, Rashdan (2007) ${ }^{(32)}$ stated that the Egyptian Nursing Syndicate encouraged to adopt an agency mission that offers protection and promotion of the welfare for the citizens of Egypt by ensuring that each person practicing as a nurse in the country of Egypt is competent to practice safely.

The present study results revealed that nurses intern feel possessing high professional and ethical competency. This means that those nurses intern have the opportunities during the internship year to recognize accountability and responsibility for their action and practice within the limits of their abilities and qualifications. This is supported by Evans $(2005)^{(24)}$ who on lined with the results of the present study and she found that high emphasis of internship program was for professional domain of competency.

The present study results revealed that nurses intern reported that internship program emphasis on possessing high 
critical thinking and analysis competency. This may be related to the internship program provided opportunities for nurses intern to transfer fundamental nursing skills from one situation to knowledge and demonstrate proficiency in skills. In concern with, Mallum (2010) (33) supported the present study results and she found that nurses intern rated themselves high in critical thinking and analysis domain competencies at the end of the program.In contrast to, Queen (2009) ${ }^{(34)}$ did not support the present study. His study evaluated 452 new graduate nurses who worked at fourteen hospitals. The results identified deficiencies in the critical thinking and interpersonal skills of the new nurses during internship program.

The present study results revealed that nurses intern perceived high emphasis of internship program put on management of care competency. It may related to that nursing interns practice holistic nursing care to patients and undertake all activities in relation to patient care and other assigned duties. In this respect, Roberts and Farrel (2008) ${ }^{(35)}$ supported the results of the present study and they stated that a period of supervised practice during internship program gave the necessary support to nurses intern to improve their management of care competencies, consolidate clinical and decision making skills, help them to orientate to the culture of the nursing profession and become an effective member of the nursing workforce.

The present study results revealed that nurses intern perceived high emphasis of internship program was put on enabling domain. It may be related to that the nurses intern communicate with flow numbers of healthcare team, patients and their relatives during different shifts and different rotations. This apparent in the active participation of the nurses intern as part of the multidisciplinary team, experience a variety of different areas of nursing specialization, understand and adapt to the culture of the hospital.
In regard to, Russel and Perris $(2007)^{(36)}$ supported the results of the present study and they found that majority of interns have rated high emphasis of preceptors during internship program on enabling domain, critical thinking domain and to achieved at least minimum level for admission and discharge competencies. Also, Arthur (2008) ${ }^{(37)}$ supported the results of the present study and she found that nurses intern rated themselves a good or strongly developed ability to provide nursing care with ability in communication with patient and a strong ability to listen to patients without diminishing their feelings.

The present study results revealed that nurses intern perceived high emphasis level of internship program was put on confidence in nursing practice. This may be related to the clinical supervision which the nurses intern received at the internship program. This clinical supervision enhanced their sense of confidence and competence. As well as, it improved their performance to job responsibilities' and patients care.Koerner and Walters $(2010)^{(38)}$ supported the results of the present study and they recognized that internship program as an effective strategy to build confidence in nursing practice by provide clinical supervision.

The present study revealed that majority of nursing interns perceived that internship program put high emphasis level on rotation. It may be related to the organized and structured rotation with enough time to permit them gain skills and abilities because it covers several clinical experience which develop their competencies and confidence. In regard to, Evans et al (2010) $)^{(39)}$ supported the results of the present study and they found that high emphasis of internship program for providing organized rotations.

The present study revealed that nursing interns reported little emphasis of internship program was put on opportunities offered in clinical environment. Those nursing interns 
mentioned their causes as they rarely access to the clinical supervisors and rarely receive feedback from them and the program coordinator. Beside they have no time to attend the sessions for orientation or educational components. Elliott $(2002)^{(40)}$ supported the results of the present study and he found that nursing interns felt unsupported clinical environment during internship year.

The present study results revealed that nursing interns perceived little emphasis level of internship program put on role of clinical supervisor. In fact nursing interns reported that clinical supervisors were not good role model in giving clinical procedures, collaboration with nurse staff or healthcare team. Also their professional role was unsatisfied to nursing interns as they did not use standards, policies and did not give reports. Really they did not adhere to the value of the profession. In respect to Modic and Schloesser $(2006)^{(41)}$ supported the present study results and they found that nurses intern perceived poor preceptors role during their internship program.

The present study revealed that nurses intern scored that internship program put little emphasis level on avoiding conflict. The fact is that those nursing interns found a lot of nonverbal innuendo and verbal affront. As well as, they found withholding information, sabotage, scapegoat and a lot of internal conflict. Beside, they failed to get respect for privacy so their confidence broken. Moreover, Delaney (2005) $)^{(42)}$ and Olson et al (2008) ${ }^{(43)}$ supported the present study results and they showed that graduates were aware of conflicting emotions regarding their transition. Furthermore, the shortage of nurses which the organization suffered and the dependence on nursing interns as a golden solution to solve this shortage with little support presented to nursing interns.

\section{Conclusion:}

As strengths points in the internship program offered at Tanta University Hospital, high emphasis $90.7 \%, 87.2 \%$ and
$80.6 \%$ of internship program was put on rotation, level of confidence in nursing practice and domains of competency according to the perception of nursing interns respectively. While as weaknesses points at the internship program, little emphasis $72.0 \%, 63.1 \%$ and $60.5 \%$ of internship program was found for the conflict management, role of supervisor and opportunities offered in clinical environment among of nursing interns respectively.

\section{Recommendations:}

Based on the results of this study it was recommended that building structured preceptor-ship program, prime importance the availability of clinical preceptors, provision of job description for those preceptors, structured orientation program, open communication and coordination between faculty and hospital, evaluating system and feedback and strategies to avoid conflict and lateral violence. In addition, further researches were needed to analyze the causes of weaknesses points of the internship program and found the strategies to solve it.

\section{References:}

1. Ellis J.R. Nursing Today's world trends, issues \&management. $9^{\text {th }}$ ed. Philadelphia: Lippincott Williams Inc, 2008: 200-201.

2. Pine $R$. and Tart $K$. Return on Investment: Benefits and challenges of a baccalaureate nursing residency program. Nursing Economics Journal. 2009, 25 (1):14.

3. Beecroft P.C., Kunzman E. and Krozek C. RN Internship outcomes of a one year pilot program. Journal of Nursing Administration. 2008, 31(12) :575-576.

4. Tanner C. and Chesla C. Expertise in nursing practice caring, clinical judgment and ethics. 2 nded, USA :Springer company, 2009:322.

5. Linn L. and Howard A. Hand book for researcher in cooperative education and internship practical, 2004:137-138. 
6. Goode C.J. and Williams C.A. Post baccalaureate nurse residency program. Journal of Nursing Administration. 2004, 34 (2) :75.

7. Gibson G. The effectiveness of an orientation program for the transitioning of new nurses. A thesis submitted to the faculty of nursing at Gonzaga University.2010: 12-14.

8. Edwin G. and Walker R. The preservice practicum: perspectives of students from three disciplines. Journal of Nursing Scholarship.2008, 19(4): 24- 25.

9. Eason A.M. Work based learning in nursing education the value of preceptorships. Journal of Clinical Nursing. 2010, 9(3): 80-81. available at http://www.healthleaders media.com. Access at 5/1/2011

10.Harrion L. Professional practical /vocational nursing. $2^{\text {nd }}$ ed. Thomson learning Inc: Canada. 2009: 260-261.

11.Paly C., Chang E.M., Daly J. Transitions in nursing: preparing for professional practice. 2 nd $\mathrm{ed}$, Austeralia :Elsevier Inc, 2009: 17-18.

12. Smith C.A. Implementing a nursing internship program. Healthcare quarterly.2008,11(2):77-78.

13. Griffin M. Teaching cognitive rehearsal as a shield for lateral violence: An intervention for newly licensed nurses. Journal of continuing Education in Nursing. 2004, 35(6): 258- 260

14. Padgett T.M. Survey of nurses' perceptions of first job experiences. A research paper at Ball State University. Indiana.2009:7-8,30.

15.Jones R.A. Preparing Tomorrow's leaders. Nursing of administration Journal. 2010,40(4): 1-2.

16. Ramani S. and Leinster S. Teaching in the clinical environment. Medical Teacher Journal. 2008,30 (1):347-349. Availablehttp://www.nd.gov/ humanservices.com. Access at 2/1/2011

17. Simpson A. J. The experience of new nursing graduates on labor and delivery units. A thesis for doctoral degree. Colledge of saint Mary. 2010: 254-259

18. Branch W.T and Paranjape A. Feedback and reflection: teaching methods for clinical settings. Journal of Nursing Administration.2009, 11(4): 197-198.

19. Owens D.L. and Jurjahcan M.A. New graduate RN internship program: a collaborative approach for system wide integration. Nurse Staff Development Journal. 2006, 17(3):144150.

20. Nurse internship \& Nurse residency frequently asked questions, 2010 available at . Access at 28/3/2011

21. Beecroft P.C., Dorey F. and Wenten M. Turnover intention in new graduate nurses: a multivariate analysis. Journal of Advanced Nursing. 2008, 62(1): 4950 .

22. Lambert S. Internships: many perspectives unlimited benefits.2010. Available at www.bec pdx.org. Access at $30 / 4 / 2011$

23. Daly J.A. and Chang E.E. Transitions in nursing. $2^{\text {nd }}$ ed. Austalia: Elsevier puplishers, 2007: 10-11.

24. Evans J. The value of transition support programs for newly registered nurses and hospitals offering the programs in new south wales. Thesis in faculty of education. Australia.2005:45-48.

25. Atherfold $\mathbf{C}$. A case study exploration of graduate nurses' preceptored experience. New Zealand.2008, available at http://www.coda.ac.hz/unitec-hs-di/g. Access at 10/1/2011

26. Center for American Nurses. Lateral violence and bulling in workplace. February 2008, 1-3.

27. Casey K., Fink R.A., Krugman M.S. and Propst J. The Graduate nurse experience. Journal of Nursing Administration.2004,34 (6):303.

28. Duchscher J.B. A process of becoming: the stages of new nursing 
graduate professional role transition. Journal of Continuing education in Nursing. 2009, 39(10):42-45.

29. Evans E. ANCI competencies : an investigation of uniqueness \& importance . Griffith university. Faculty of Nursing. A thesis requirement for the degree of Doctor of philosophy.2009:1-3.

30. Good W.E., Escola L.N. and Powell S.A. Evaluating the effectiveness of internship program among new graduated nurses. Journal of Nursing Scholarship.2009,3(4): 17-18.

31. Ashlock C.H., Afica L.M. and Carman M.L. Improving retention, confidence and competency of new graduate nurses. Nursing Economic\$ Journal. 2010,28(6) :366-368.

32. Rashdan T. Implications for advancement of Egyptian nursing: Inputs equal Outputs. White paper for Fulbright Academy Workshop in Doha, 2007. Available at www.fulbrightAcademy.org. access at 22/2/2012

33. Mallum J. Micu residency development of a unit based registered nurse program. Thesis for doctoral degree. California University. 2010: 68-70. Available at www.health leader media.com. Access at 26/2/2011

34. Queen U.S. Competencies Needed By New Baccalaureate Graduates. Nursing Education Perspectives, July 2009.3032.
35. Roberts K.J. and Farrel G. Expectations and Perceptions of Graduates' Performance at The Start and at The End of Their Graduate Year. Collegian, 2008; 10(2):13-18.

36. Russel A.L., Perris K.S.Telementoring in communal models of learning and Tutoring. Journal of Healthcare Management. 2007, 11 (2) 228-230.

37. Arthur D. Assessing nursing students' basic communication and interviewing skills: the development and testing of a rating scale. Journal of Advanced Nursing. 2008, 29(3): 658-659.

38. Koerner D.N. and Walters K.W. Supporting the new graduate in practice. 2010:1-2. available at www.support the new graduate.com. Access at 16/1/2011

39. Evans J.A., Boxer E.B. and Sanber S.A . Strengths and weaknesses of transitional support programs for newly registered nurses. Australian Journal of Advanced Nursing. 2010, 25(4): 17-18.

40. Elliott M. The clinical environment a source of stress for undergraduate nurses. Australian Journal of Advanced Nursing. 2002, 20(1):34.

41. Modic M.F. and Schloesser L.M. Preceptorship. Journal of Nurses in Staff Development.2006, 14(7): 52-54.

42. Delaney E. Graduate nurses' transition from student to professional nurse. Journal of Scholarship. 2005, 16(9) 21-23

43. Olson R.C., Nelson M.A., Stuart C.C. and Young L.A. A model for seamless transition from nursing student to registered nurse. Journal of Nursing Administration.2008, 31(1) :40-41. 